OPEN ACCESS

Edited by:

Simona Bonavita,

University of Campania Luigi

Vanvitelli, Italy

Reviewed by:

Emanuele D'Amico,

University of Catania, Italy

*Correspondence:

Tjalf Ziemssen

tjalf.ziemssen@uniklinikum-dresden.de

Specialty section:

This article was submitted to

Multiple Sclerosis and

Neuroimmunology,

a section of the journal

Frontiers in Neurology

Received: 23 October 2020

Accepted: 30 April 2021

Published: 05 August 2021

Citation:

Ziemssen T, Hoffmann F, Richter S, Engelmann $U$ and White $R$ (2021)

Alemtuzumab in a Large Real-Life

Cohort: Interim Baseline Data of the TREAT-MS Study.

Front. Neurol. 12:620758. doi: 10.3389/fneur.2021.620758

\title{
Alemtuzumab in a Large Real-Life Cohort: Interim Baseline Data of the TREAT-MS Study
}

\section{Tjalf Ziemssen ${ }^{1 *}$, Frank Hoffmann ${ }^{2}$, Stephan Richter ${ }^{3}$, Ulrich Engelmann ${ }^{4}$ and Robin White ${ }^{4}$ on behalf of the TREAT-MS Study Group}

${ }^{1}$ Department of Neurology, Center of Clinical Neuroscience, Carl Gustav Carus University Hospital, Dresden, Germany, ${ }^{2}$ Klinik für Neurologie, Krankenhaus Martha-Maria Halle-Doelau, Halle (Saale), Germany, ${ }^{3}$ Zentrum für Neurologie und Psychiatrie, MIND, Stuttgart, Germany, ${ }^{4}$ Medical Affairs, Sanofi-Aventis Deutschland GmbH, Neu-Isenburg, Germany

The non-interventional long-Term study foR obsErvAtion of Treatment with alemtuzumab in active relapsing-remitting MS (TREAT-MS) study collects the so far largest real-life cohort regarding utilization, long-term effectiveness, and safety of alemtuzumab, a humanized monoclonal antibody directed against the cell surface glycoprotein CD52, in adult patients with active relapsing-remitting multiple sclerosis (RRMS). An interim analysis of baseline parameters at inclusion of a non-interventional real-world study about alemtuzumab in Germany including previous multiple sclerosis (MS) medication utilization, MS activity, severity, and duration, as well as comorbidities was performed. Of the 883 patients, $71.6 \%$ were women. Mean age was $35.7 \pm 9.2$ years, time since first MS symptoms (=disease duration) is $8.0 \pm 6.8$ years, and Expanded Disability Status Scale (EDSS) is $2.7 \pm 1.8$ points (range, $0.0-7.5$ points). The number of relapses in the 12 and 24 months prior to inclusion were $1.6 \pm 1.2$ and $2.2 \pm 1.8$, respectively. Of the patients, $14.4 \%$ were treatment naive, while for the majority, a wide spectrum of MS disease-modifying treatments (DMTs) and treatment sequences were documented. Overall, interferon beta (IFN-beta) was reported most frequently $(52.4 \%)$, followed by fingolimod (35.2\%), natalizumab (34.9\%), and glatiramer acetate (28.9\%). Patients with longer disease duration and higher EDSS had a higher number of previous DMTs. Compared to the pivotal phase 2/3 studies, RRMS patients starting alemtuzumab treatment had a longer disease duration in real-world conditions. There was variety of different treatment sequences before the final switch to alemtuzumab. In the future, linking these treatment sequences or other baseline characteristics with effectiveness and safety outcomes might be useful to support treatment decisions. Registered at Paul-Ehrlich-Institut under NIS 281.

Keywords: alemtuzumab, non-interventional study, risk-management plan, Germany, real world data, multiple sclerosis, effectiveness, safety

\section{INTRODUCTION}

The treatment landscape for multiple sclerosis (MS) has substantially changed, with the approval of more than 10 new drugs in the last decade. High-efficacy treatments appear to improve the longterm outcomes of MS patients (1) but are often only considered as second- or third-line options due to label restrictions or at the discretion of the treating physician. Two general treatment paradigms 
can be applied, either a maintenance-escalation approach, where a medication is given continuously and patients are switched to a higher efficacy drug upon disease activity, or a pulsed immune reconstitution therapy, which involves few treatment pulses with long intermittent treatment-free phases (2). Alemtuzumab (Lemtrada ${ }^{\circledR}$, Sanofi Genzyme) is given as a pulsed immune reconstitution therapy in usually two treatment phases, which leads to sustained and treatment-free effectiveness $(3,4)$. Alemtuzumab is a humanized monoclonoal IgG1kappatype antibody binding to the cell surface protein CD52, which is expressed in large amounts on B and T lymphocytes (5). After binding of alemtuzumab to CD52, circulating lymphocytes are depleted either by complement-induced or antibody-dependent cell-mediated cytotoxicity (6). After depletion, B- and Tlymphocyte repopulation occurs in a defined pattern and has demonstrated beneficial long-term effects (7).

Overall, alemtuzumab appears to reprogram the immune repertoire, which manifests in the special kinetics of immune cell populations, the increased production of antiinflammatory cytokines, and the very long duration of action (8). Three randomized, rater-blinded clinical trials assessing the efficacy of alemtuzumab in MS treatment, using an effective comparator drug, have been performed: CAMMS223 (9), CARE-MS I (10), and CARE-MS II (11). In sum, alemtuzumab significantly reduced clinical and radiological disease activity and slowed down progression of relapsing-remitting MS (RRMS) to secondary progressive MS, also in the long-term and in patients with highly active disease (HAD) $(4,12-15)$.

In the European Union, in 2013, alemtuzumab has been marketed as a treatment for RRMS with active disease defined by clinical or imaging features. In the USA, in 2014, the drug has been approved for RRMS and progressive-relapsing MS treatment but only for patients who did not have a satisfying response to two or more drugs (16) (i.e., for thirdline therapy). In 2019, alemtuzumab has undergone a procedure under Article 20 of Regulation (EC) No 726/2004 resulting from pharmacovigilance data, which led to label change effective January 2020 (17). Alemtuzumab should now only be used to treat RRMS if the disease is highly active despite treatment with at least one disease-modifying therapy or if the disease is worsening rapidly (18). Alemtuzumab must also no longer be used in patients with certain heart, circulation, or bleeding disorders or in patients who have autoimmune disorders other than multiple sclerosis.

Data on the utilization and the treatment outcomes of alemtuzumab in the real-world clinical practice are limited to few reports on small, mostly monocentric cohorts $(19,20)$ or a retrospective data collection, respectively (21). There is a need for high-quality, comprehensive, and valid real-life evidence data, as these data cover additional aspects of patient care and expand the data available by complementary information $(22,23)$.

The aim of the non-interventional long-Term study foR obsErvAtion of Treatment with alemtuzumab in active relapsing-remitting MS (TREAT-MS) study is to establish a broader real-world database on the utilization and effectiveness, safety, and other aspects of the drug in everyday clinical practice in Germany (24). The current interim analysis describes the cohort of patients before the alemtuzumab label change with particular focus on the treatment profile, disease characteristics, and comorbidities before alemtuzumab start.

\section{DESIGN AND METHODS}

\section{Design}

TREAT-MS is a prospective and retrospective, multicenter, openlabel, non-interventional long-term study that collects data from neurologists in specialized MS centers (clinics or outpatient departments) in Germany (24). The study was registered in a publicly accessible database at Paul-Ehrlich Institute (regulatory authority) under NIS 281.

\section{Patients}

Patients are eligible for documentation if they are newly treated with alemtuzumab or have initiated treatment earlier and are followed up on the long term.

\section{Study Flow and Parameters}

Study parameters include the following: demographics, comorbidities, MS anamnesis and characteristics including relapses over time, Expanded Disability Status Scale (EDSS), lesions on MRI, and as patient-related outcomes, Symbol Digit Modality Test (SDMT), Patient-Reported Indices for MS (PRIM US), EuroQol 5D-3L, and Work Productivity and Activity Impairment Questionnaire (WPAI) (25). The Clinical Global Impression-Severity (CGI-S) test expresses the experience-based impression of the treating physician on the severity of the patient's illness in a 7-point scale (26). Analogously, the CGI-S can be determined by the patient to show the evaluation of the patient on his or her clinical condition.

\section{Treatment}

Alemtuzumab is administered as two annual courses (on 5 consecutive days at baseline and on 3 consecutive days 12 months later), and patients are followed up for safety as per local labeling. Patients could receive up to two additional courses $(12 \mathrm{mg} /$ day $\times 3$ days) $\geq 12$ months after the most recent course or treatment with other DMTs as needed.

Neurologists and MS nurses were guided by the MS documentation system for physician, nurse, and patient (MSDS 3D) Lemtrada-TREAT-MS module through the entire management of treatment, including monitoring of the first and second infusion courses, necessary examinations, and regular laboratory screenings $(27,28)$.

Statistical analyses were performed in an exploratory manner using descriptive statistical methods. For continuous variables, the number of patients with non-missing and missing data, mean, standard deviation, minimum, 25\% quantile, median, $75 \%$ quantile, and maximum were calculated. For ordinal and categorical variables, frequencies were calculated. Incomplete data sets were included in the analysis. Imputations were only done for missing dates for days (substituted by the 15) and for months (substituted by June), while years were not substituted. Given the descriptive character of the study, no further imputations were deemed appropriate. 
No sensitivity analyses were done.

A treatment pathway is defined as a unique longitudinal sequence of discrete MS treatments [disease-modifying therapies $(\mathrm{DMT})]$ and is differentiated based on introduction of discrete DMTs in patients' MS treatment course. Treatment pathways were visualized in Sankey diagrams, generated through SAS, version 9.4 (SAS Institute Inc., Cary, NC, USA) (29). As another visualization approach, scatterplots were generated based on Multiple Sclerosis Severity Score (MSSS), which relates scores on the EDSS to the distribution of disability in patients with comparable disease durations (30).

The total cohort at the data cutoff date February 10, 2020 comprised 883 patients. Statistical analyses were done with IBM SPSS for Windows, Version 15.0.0.

\section{RESULTS}

\section{Setting}

Of all physicians who contributed at least one eligible patient for the present analysis, 41 (34.7\%) were hospital-based and 77 $(65.3 \%)$ were resident neurologists. Data from $426(48.2 \%)$ and $457(51.8 \%)$ patients were documented by hospital-based and resident neurologists, respectively.

\section{Baseline Characteristics of Patients}

Baseline characteristics of the 883 patients are summarized in Table 1. Mean age at baseline was $35.7 \pm 9.2$ years (range, 1663 years). The majority (71.6\%) were female. Mean time since first MS symptoms (=disease duration) was $8.0 \pm 6.8$ years and since MS diagnosis was 7.2 \pm 6.3 years. The median EDSS was 2.5, with a range from 0.0 to 7.5 . While $63.2 \%$ of the patients had an EDSS $\leq 3,36.8 \%$ had a baseline EDSS $>3$. Figure 1 displays the distribution of EDSS categories. The mean number of relapses in the $12 / 24$ months prior to inclusion was $1.6 \pm 1.2 / 2.2 \pm$ 1.8. Clinical Global Impression (CGI) assessed by the physician or patients at inclusion assessment was $4.8 \pm 2.7$ and $3.2 \pm$ 1.7 , respectively.

\section{MS Pre-treatment With DMT}

About every seventh patient $(n=127 ; 14.4 \%)$ was treatment naive. In contrast, $722(81.7 \%)$ had received any DMT $(3.9 \%$ unknown). In detail, $21.7,30.4,18.5,9.5$, and $2.3 \%$ had received one, two, three, four, or five or more pretreatments with MS medications, respectively.

The MS treatment history before the initiation of alemtuzumab is listed by decreasing frequency in Table 2. Interferon-beta (IFN-beta) was reported most frequently (52.4\%), followed by fingolimod (35.2\%), natalizumab (34.9\%), and glatiramer acetate (28.9\%). With regard to the last MS medication before alemtuzumab initiation, $22.0 \%$ received fingolimod, $14.8 \%$ natalizumab, and $8.6 \%$ IFN-beta therapy.

\section{Characterization of the Disease Status at Baseline}

The EDSS, the duration since initial MS symptoms, and the number of MS relapses in the previous year are useful parameters to evaluate the disease status. In order to visualize these
TABLE 1 | Baseline characteristics.

\begin{tabular}{|c|c|c|}
\hline \multirow[t]{2}{*}{ Variable } & \multicolumn{2}{|c|}{ Total cohort } \\
\hline & $N$ & Value \\
\hline Age (years) & 883 & $35.7 \pm 9.2$ \\
\hline Range & & $16-63$ \\
\hline Sex, Female, \% & 632 & 71.6 \\
\hline Male, \% & 251 & 28.4 \\
\hline \multicolumn{3}{|c|}{ Multiple sclerosis characteristics } \\
\hline $\begin{array}{l}\text { Time (years) since first MS } \\
\text { symptoms until inclusion into } \\
\text { study }\end{array}$ & 668 & $8.0 \pm 6.8$ \\
\hline $\begin{array}{l}\text { Time (years) since MS } \\
\text { diagnosis until inclusion into } \\
\text { study }\end{array}$ & 793 & $7.2 \pm 6.3$ \\
\hline RRMS, \% & 823 & 95.4 \\
\hline \multicolumn{3}{|l|}{$\begin{array}{l}\text { Relapses during last } 12 \\
\text { months before inclusion } \\
\text { into study, } \%\end{array}$} \\
\hline 0 & 127 & 16.3 \\
\hline 1 & 295 & 37.8 \\
\hline 2 & 221 & 28.3 \\
\hline 3 & 87 & 11.1 \\
\hline Missing & 102 & \\
\hline Mean \pm SD & 781 & $1.6 \pm 1.2$ \\
\hline \multicolumn{3}{|l|}{$\begin{array}{l}\text { Relapses during last } 24 \\
\text { months before inclusion } \\
\text { into study, \% }\end{array}$} \\
\hline 0 & 89 & 12.7 \\
\hline 1 & 187 & 26.6 \\
\hline 2 & 182 & 25.9 \\
\hline 3 & 128 & 18.2 \\
\hline Missing & 181 & \\
\hline Mean \pm SD & 702 & $2.2 \pm 1.8$ \\
\hline \multicolumn{3}{|l|}{$\begin{array}{l}\text { Magnetic resonance } \\
\text { imaging }\end{array}$} \\
\hline $\begin{array}{l}\text { Contrast medium enhancing } \\
\text { lesions present at 1st } \\
\text { pretreatment visit, \% }\end{array}$ & 397 & 54.7 \\
\hline \multicolumn{3}{|l|}{ Gd+ lesions } \\
\hline 0 & 226 & 31.4 \\
\hline 1 & 69 & 9.6 \\
\hline 2 & 56 & 7.8 \\
\hline $3+$ & 96 & 13.3 \\
\hline \multicolumn{3}{|l|}{ T2 lesions } \\
\hline 0 & 38 & 4.8 \\
\hline 1 & 16 & 2.0 \\
\hline 2 & 10 & 1.3 \\
\hline $3+$ & 174 & 21.8 \\
\hline EDSS total & 798 & $2.7 \pm 1.8$ \\
\hline$\leq 3$ & 504 & 63.2 \\
\hline$>3$ & 294 & 36.8 \\
\hline
\end{tabular}

EDSS, Expanded Disability Status Scale, RRMS, relapsing-remitting multiple sclerosis. Values are percentages or means \pm standard deviation (SD). 


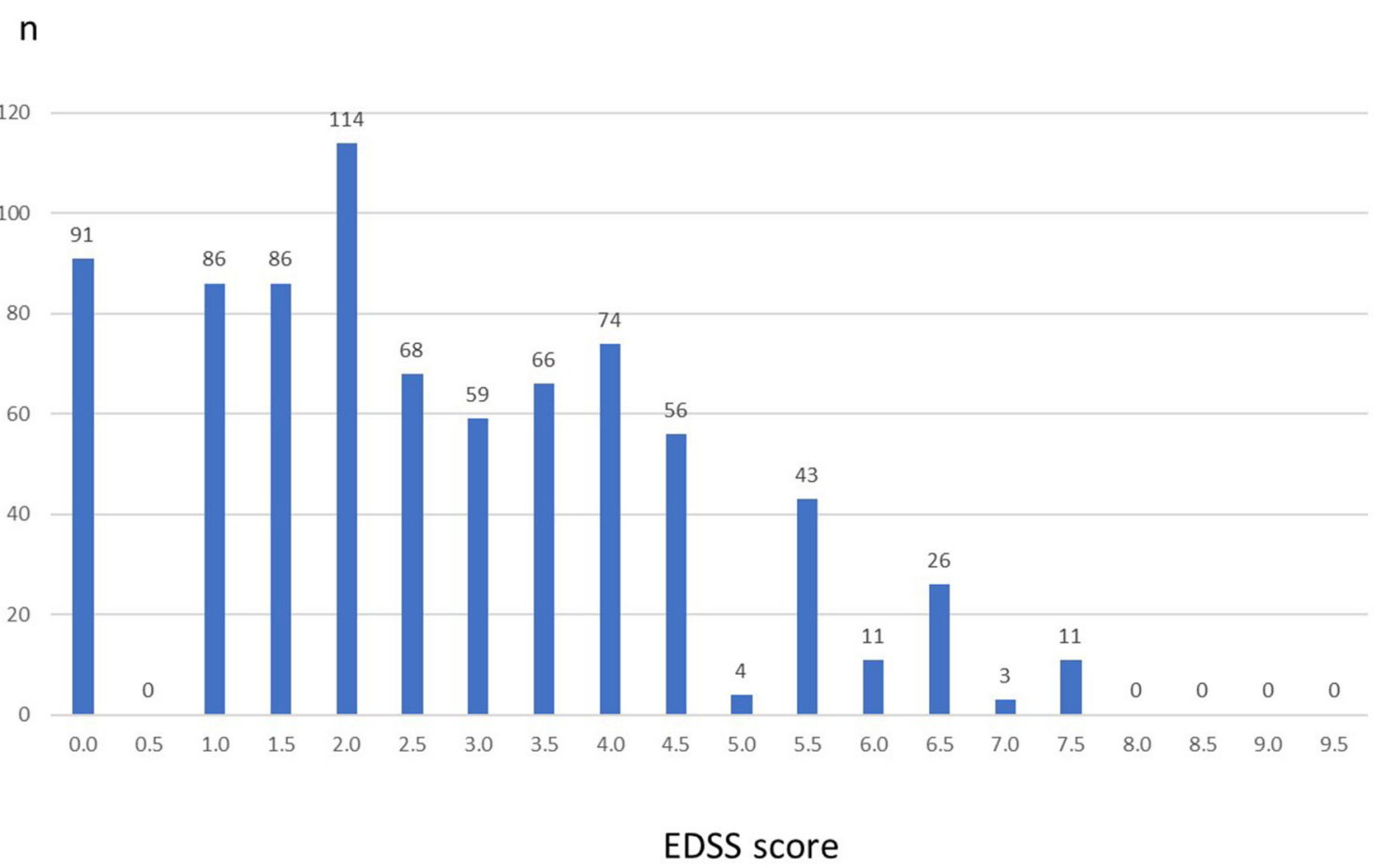

FIGURE 1 | Expanded Disability Status Scale (EDSS) at baseline $(n=883)$. Columns represent number of patients for each EDSS value. There were no patients with values above 7.5.

TABLE 2 | Disease-modifying treatments (DMTs) pretreatment.

\begin{tabular}{lc}
\hline DMT pre-treatment & Total $(\boldsymbol{N}=\mathbf{8 8 3})$ \\
& $\boldsymbol{n}(\%)$ \\
\hline Total & $727(82.3)$ \\
Interferon-beta & $463(52.4)$ \\
Fingolimod & $311(35.2)$ \\
Natalizumab & $308(34.9)$ \\
Glatiramer acetate & $255(28.9)$ \\
Other & $131(14.8)$ \\
Dimethyl fumarate & $109(12.3)$ \\
Teriflunomide & $44(5.0)$ \\
Mitoxantrone & $18(2.0)$ \\
Azathioprine & $9(1.0)$ \\
Unknown & $5(0.6)$ \\
Methotrexate & $2(0.2)$ \\
Rituximab & $1(0.1)$
\end{tabular}

Values are $n$ and percentages of total.

a "Other" includes unspecified drugs in 31 patients, daclizumab in 20 patients, immunoglobulins in six patients, and a variety of other drugs in the remaining patients.

parameters and to relate them to the number of previous MS medications, scatterplots were used combining the parameters. This allows an evaluation of the MS disease status of TREAT-MS alemtuzumab-treated patients at baseline.
The scatterplots (Figures 2A-D) show the distribution of EDSS values (y-axis) vs. disease duration (years before inclusion into the study, $\mathrm{x}$-axis) by DMT pretreatment and described in detail in the figure legend.

Each dot in the diagram represents one patient's value in relation to both parameters at baseline. For pretreated patients, the most recent DMT is distinguished by different symbols as indicated in the legend, and the basic therapies glatiramer acetate, dimethyl fumarate (DMF), interferon-beta, and teriflunomide are colored red so that they can be easily distinguished from escalation therapies. The horizontal bars on the right show the distribution (histogram with frequencies in percent) of EDSS values and the vertical bars above the scatterplot the distribution of time intervals across all patients (percentage). In treatment-naive patients, the majority had a short disease duration (in two-thirds of patients $<1$ year before inclusion) and were predominantly in the lower EDSS categories (with peaks at 0-2 and 3.5) (Figure 3A). In patients who previously received one DMT, the EDSS pattern does not differ much. In contrast, the time pattern does, since peaks occur 2 years after diagnosis and after $10+$ years. The distribution of the various DMTs appears similar across the different EDSS and the different time periods, respectively. The majority of patients received baseline therapies as indicated by the red color (Figure 3B). In patients previously treated with two DMTs, a trend to higher EDSS values is visible. Furthermore, the proportion of patients with long disease duration $(10+$ years) is nearly at $50 \%$. Fewer patients are on interferon beta 
A

o DMTs

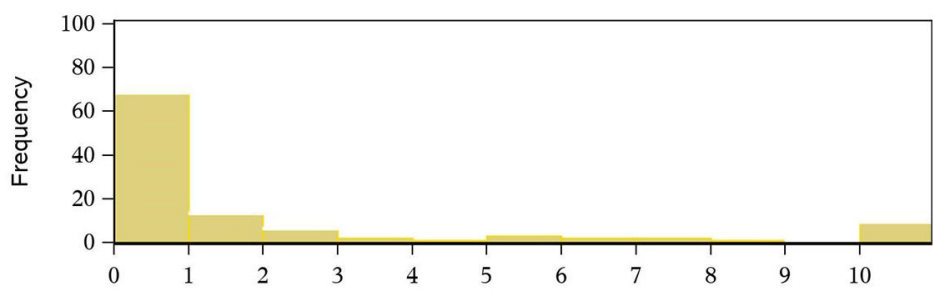

- No DMT
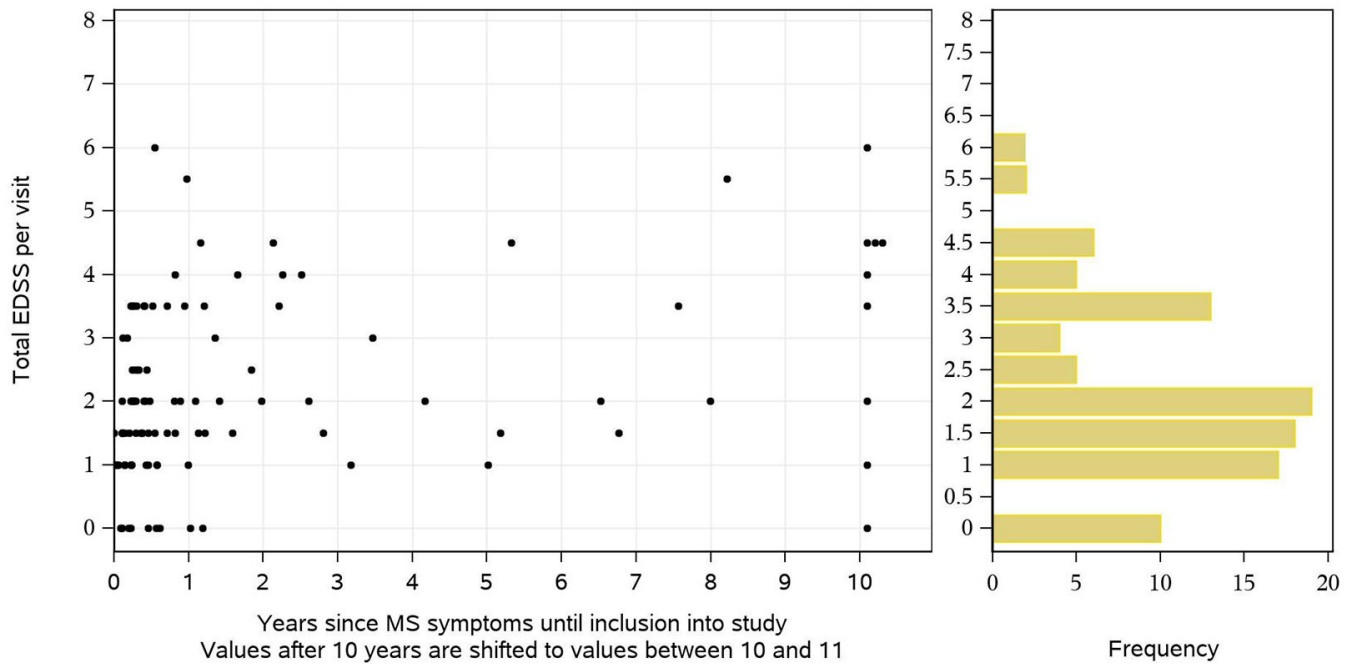

B

1 DMT

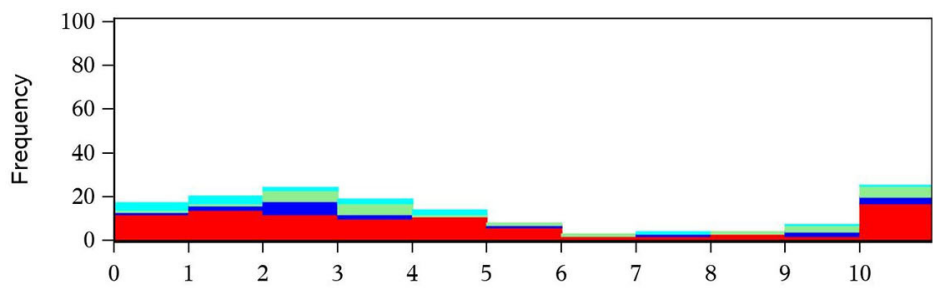

- Teriflunomide

- Other

Natalizumab

- Interferon beta

- Giatramer aceta

Fingolimod

Dimethyl fumarate
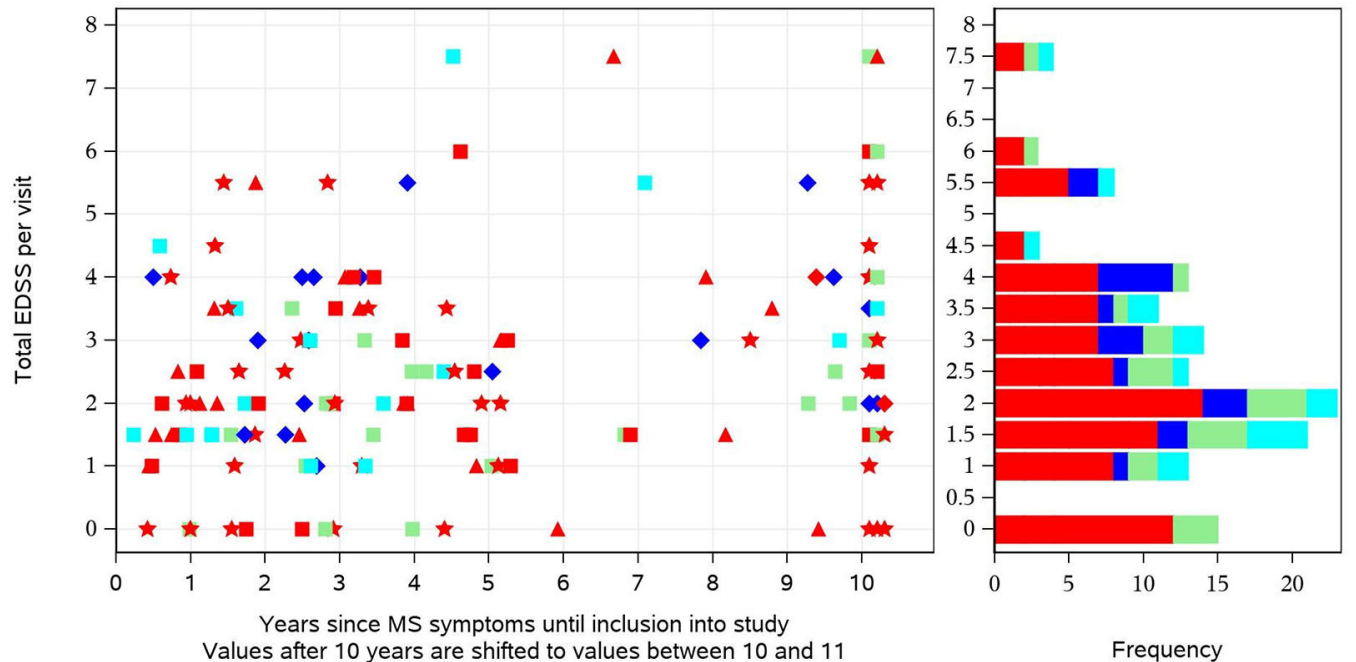

FIGURE 2 | Continued 
C

2 DMTs

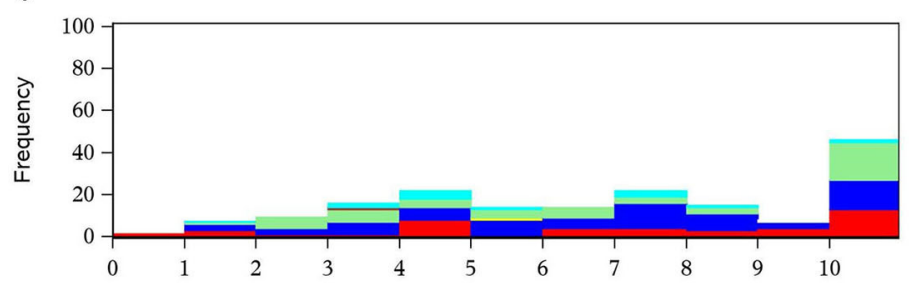

Teriflunomide

- Rituximab

Other

Natalizumab

- Natalizumab

* Interferon beta

Alatiramer acetate

Fingolimod

Azathioprine

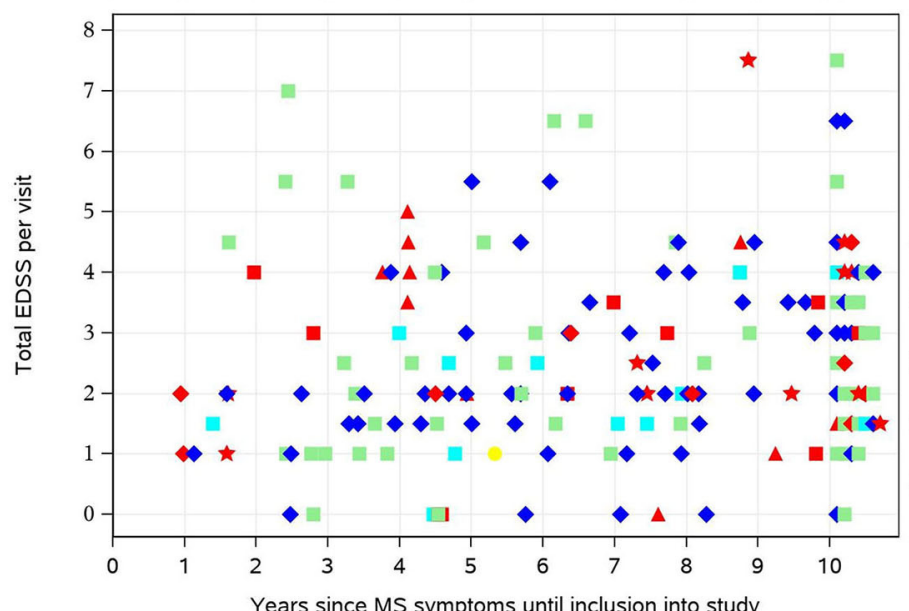

Values after 10 years are shifted to values between 10 and 11

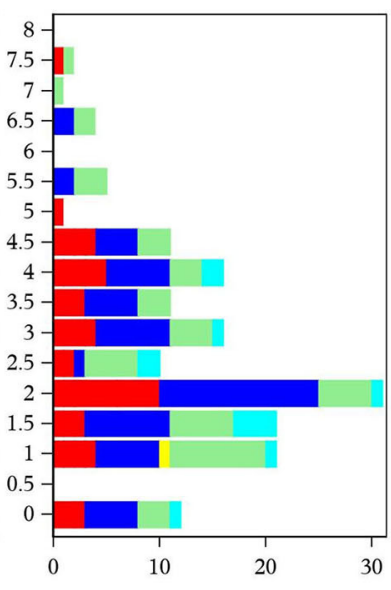

Frequency

D

$>2$ DMTs

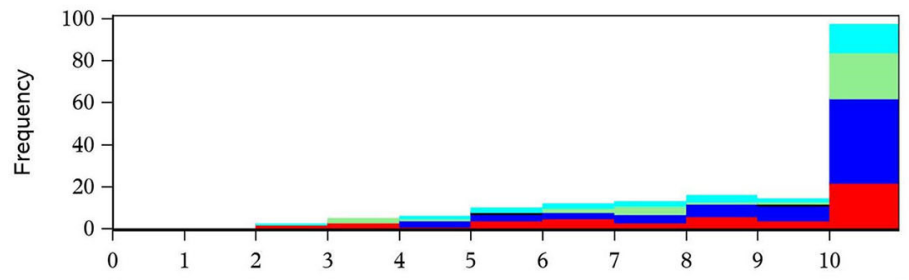

- Teriflunomide

- Other

Natalizumab

$\diamond$ Mitoxantron

Mitoxantron
Interferon beta

Alatiramer acetate

- Fingolimod

Fingolimod
Dimethyl fumarate

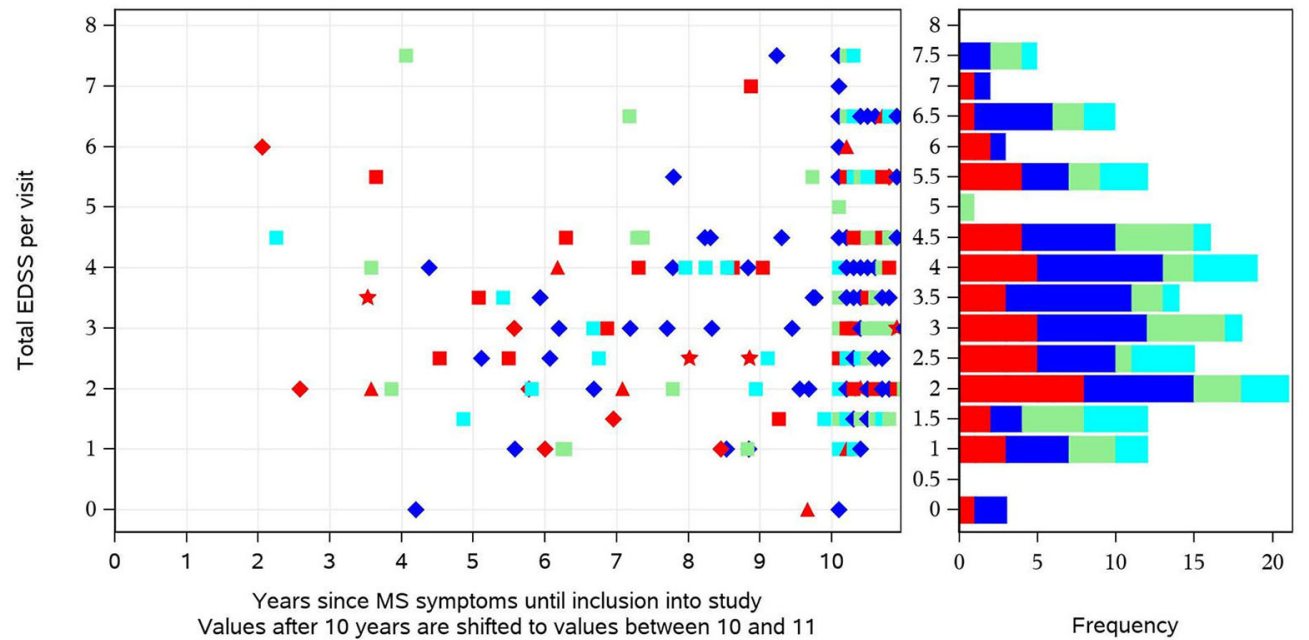

FIGURE 2 | (A-D) Distribution of Expanded Disability Status Scale (EDSS) values (y-axis) vs. disease duration before inclusion into the study (x-axis) by disease-modifying treatment (DMT) pretreatment. Each dot in the diagram represents one patient's value in relation to both parameters at baseline. For pretreated patients, the most recent DMT is distinguished by different symbols as indicated in the legend and the basic therapies glatiramer acetate, dimethyl fumarate (DMF), interferon-beta, and teriflunomide are colored red so that they can be easily distinguished from escalation therapies. The horizontal bars on the right show the distribution (histogram with frequencies in percent) of EDSS values, the vertical bars above the scatterplot the distribution of time intervals across all patients (percentage). 
A

o DMTs

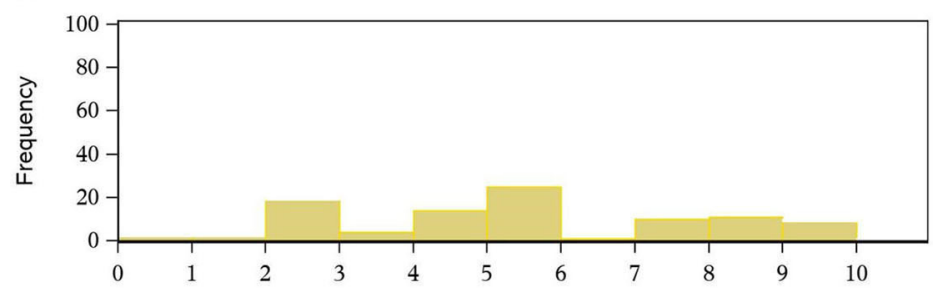

- No DMT
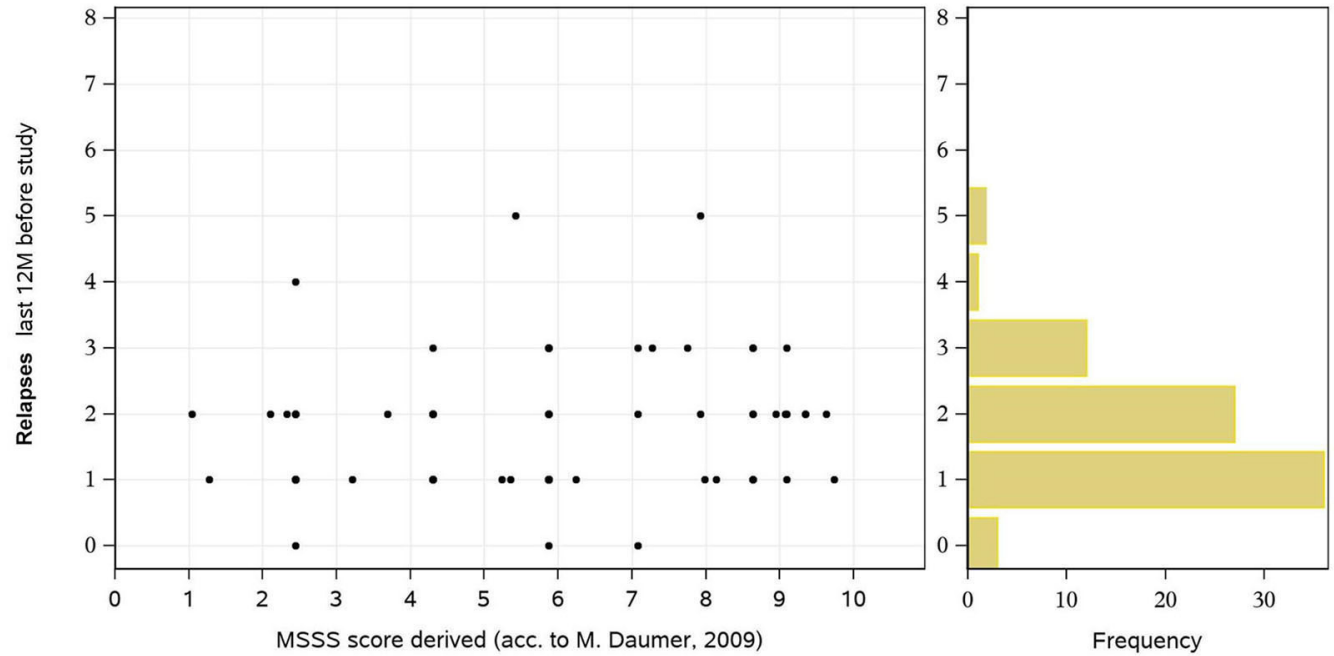

B

1 DMT

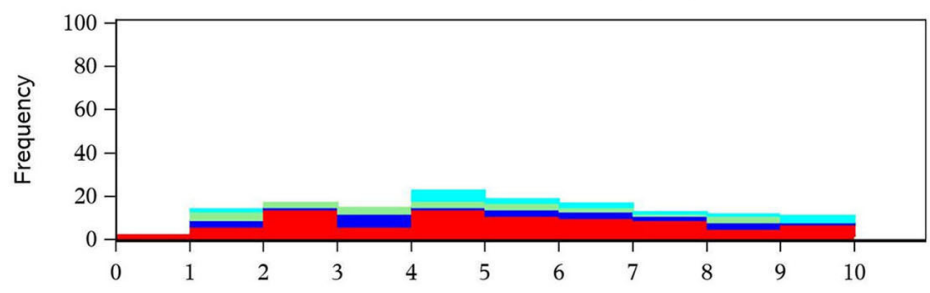

- Teriflunomide

1 Other

1. Natalizumab

^ Interferon beta

A Glatiramer acetate

- Fingolimod

Dimethyl fumarate
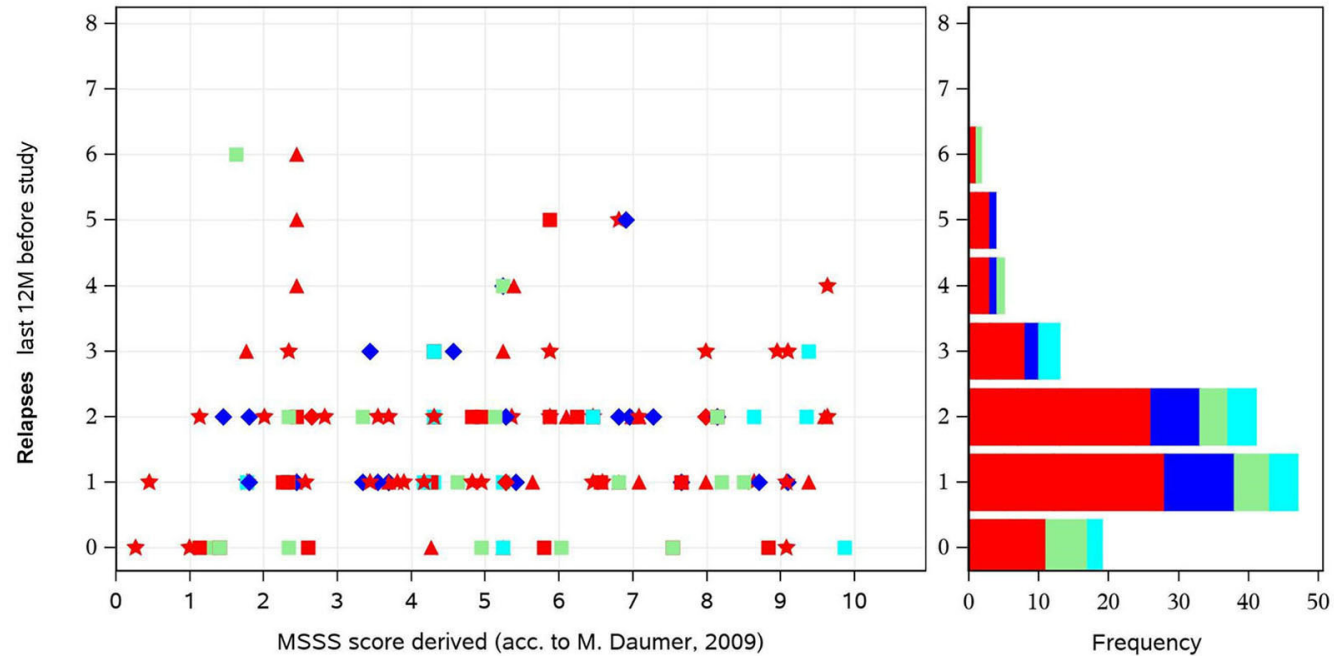

FIGURE 3 | Continued 

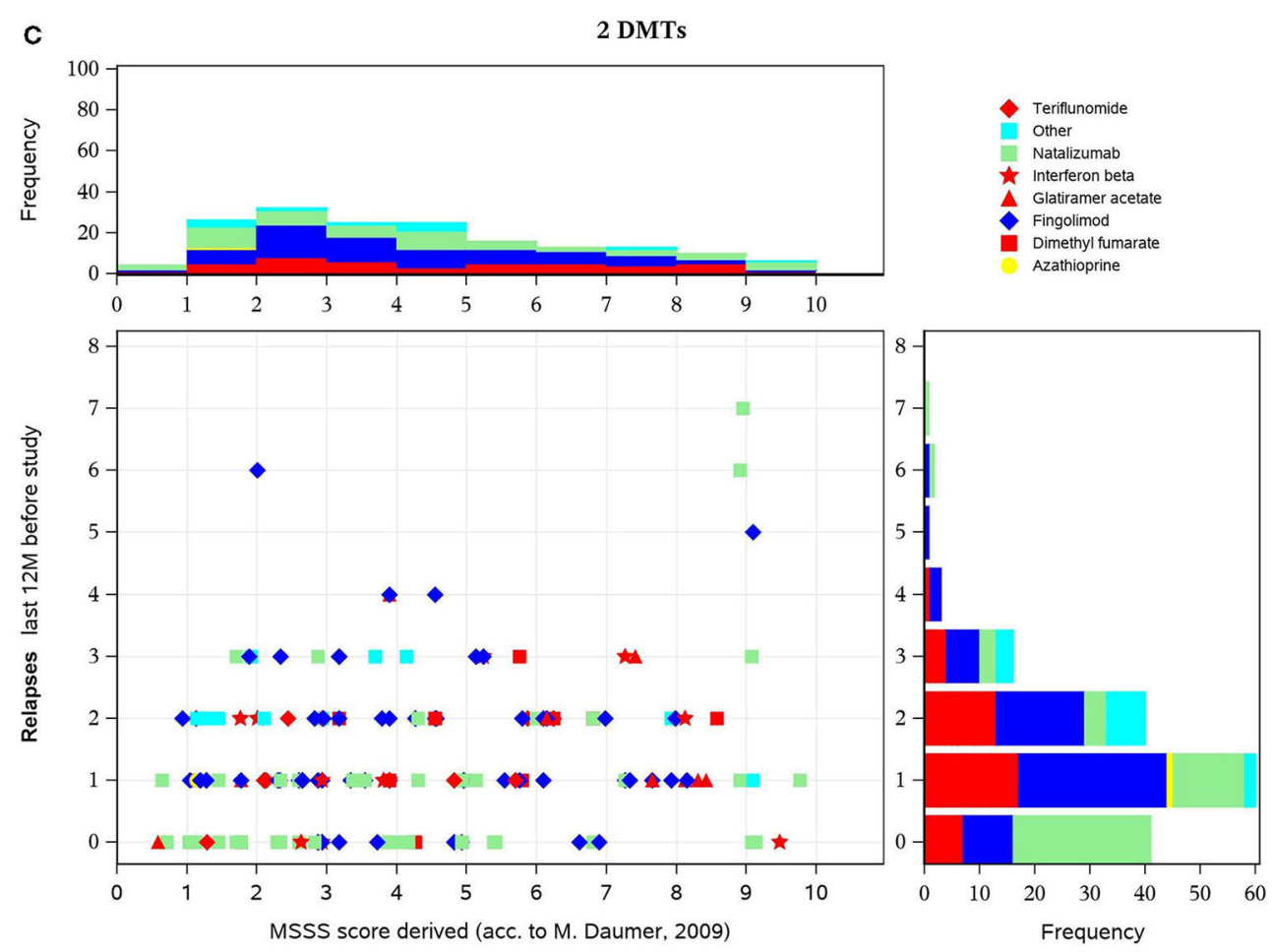

D

$>2$ DMTs

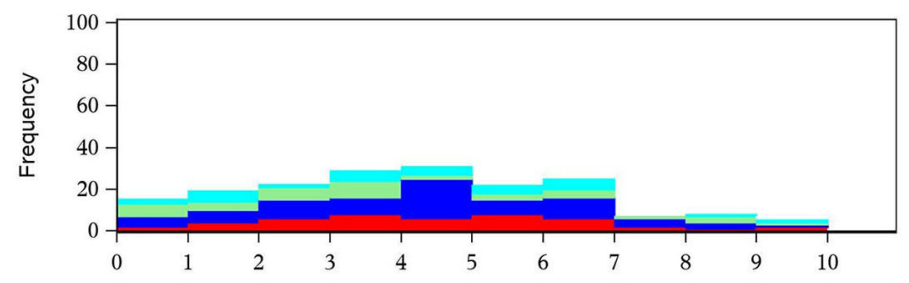

- Teriflunomide

- Other

1. Natalizumab

Interferon beta

Glatiramer acetate

Fingolimod
Dimethyl fumarate
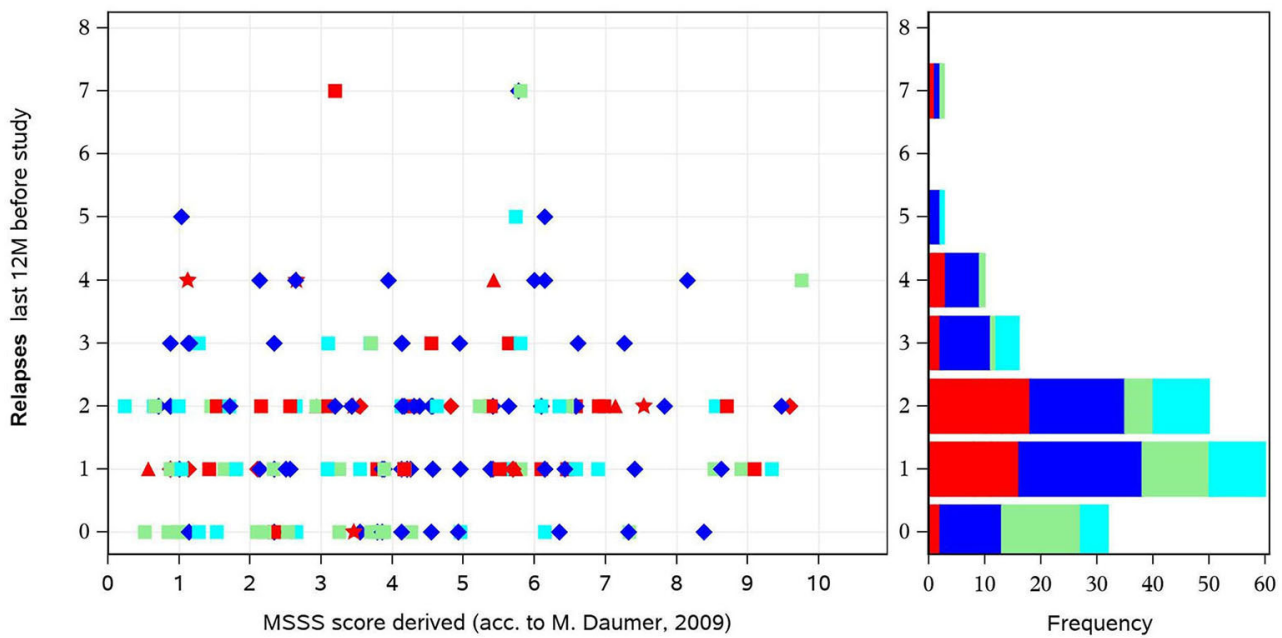

FIGURE 3 | (A-D) Multiple Sclerosis Severity Score (MSSS) (y-axis) vs. number of exacerbations (x-axis) in the 12 months before inclusion, by disease-modifying treatment (DMT) pretreatment. These figures display scatterplots of MSSS (x-axis) vs. number of relapses (y axis) in the 12 months before inclusion, in patients with no, one, two, or more DMT at baseline. In all subgroups, there was a peak of one or two relapses and a similar distribution with a predominance of lower MSSS values. There is no distinct pattern of medication use in the various groups. However, escalation therapy is more often used in patients with a higher number of disease-modifying treatments (DMTs). 
TABLE 3 | Most frequent treatment pathways prior to switch to alemtuzumab.

DMT pre-treatment

n Patients

$\%$ Of total $(N=$

886)

\section{First}

Second

Third

Interferon-beta

Interferon-beta

Interferon-beta

Natalizumab

Dimethyl fumarate

Interferon-beta

Fingolimod

Glatiramer acetate

Other

Glatiramer acetate

Interferon-beta

Interferon-beta

Interferon-beta

Interferon-beta

Glatiramer acetate

Second

Third

\begin{tabular}{|c|c|}
\hline Fingolimod & \\
\hline \multicolumn{2}{|l|}{ Natalizumab } \\
\hline Natalizumab & Fingolimod \\
\hline \multicolumn{2}{|l|}{ Fingolimod } \\
\hline Interferon-beta & Fingolimod \\
\hline Glatiramer acetate & Fingolimod \\
\hline \multicolumn{2}{|l|}{ Glatiramer acetate } \\
\hline \multicolumn{2}{|l|}{ Dimethyl fumarate } \\
\hline Natalizumab & \\
\hline
\end{tabular}

In line with three DMTs, patients received the named three drugs in the order first-second-third before switching to alemtuzumab.

Values are $n$ and percentages of total.

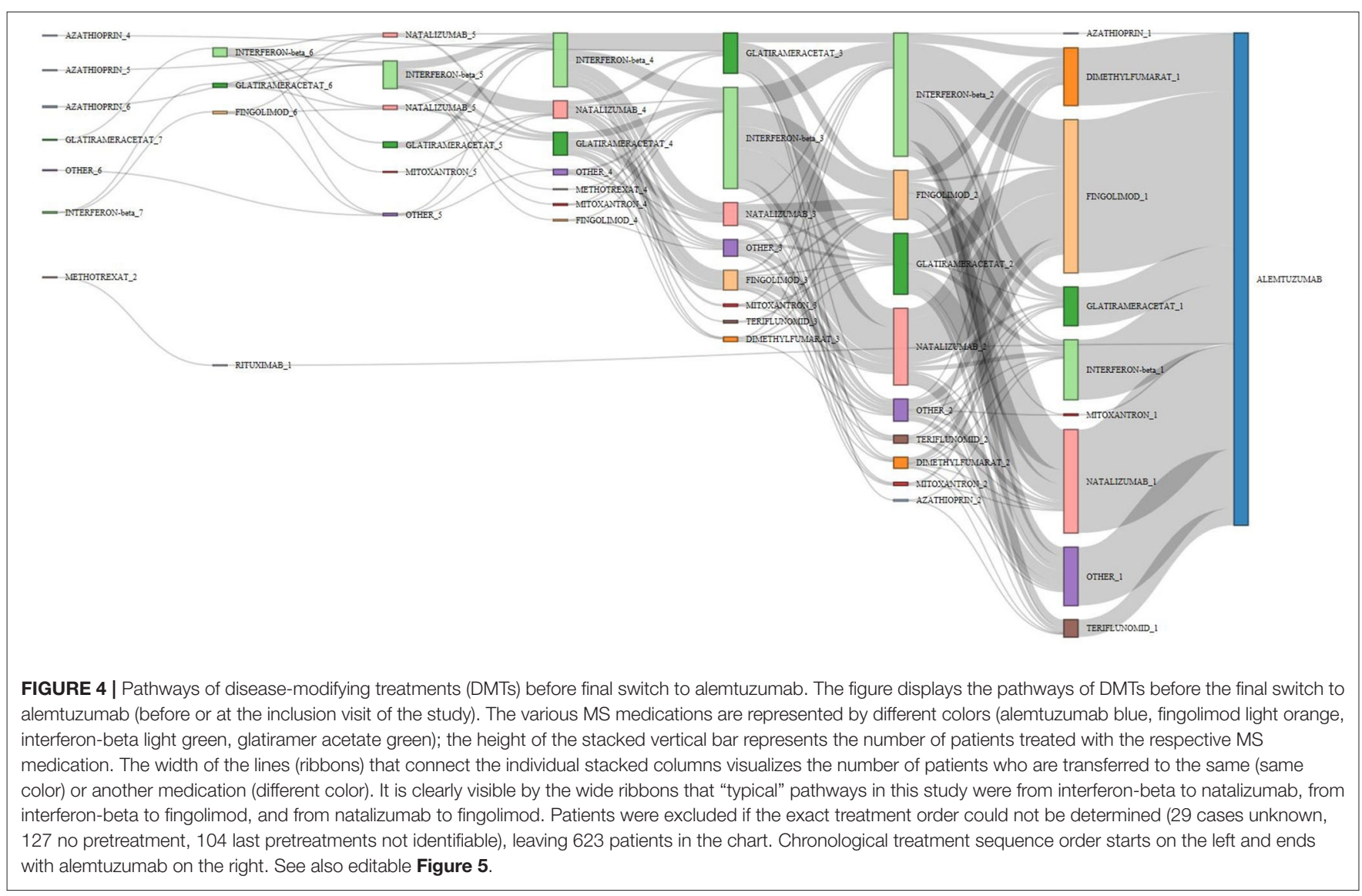

and more are on fingolimod, natalizumab, and other DMTs. Overall, the proportion of basic therapies (red) was lower compared to patients with one DMT (Figure 3C). In patients pretreated with three or more DMTs, the described changes are even more pronounced: compared to the previously described subgroups, a higher proportion of patients have a higher EDSS 


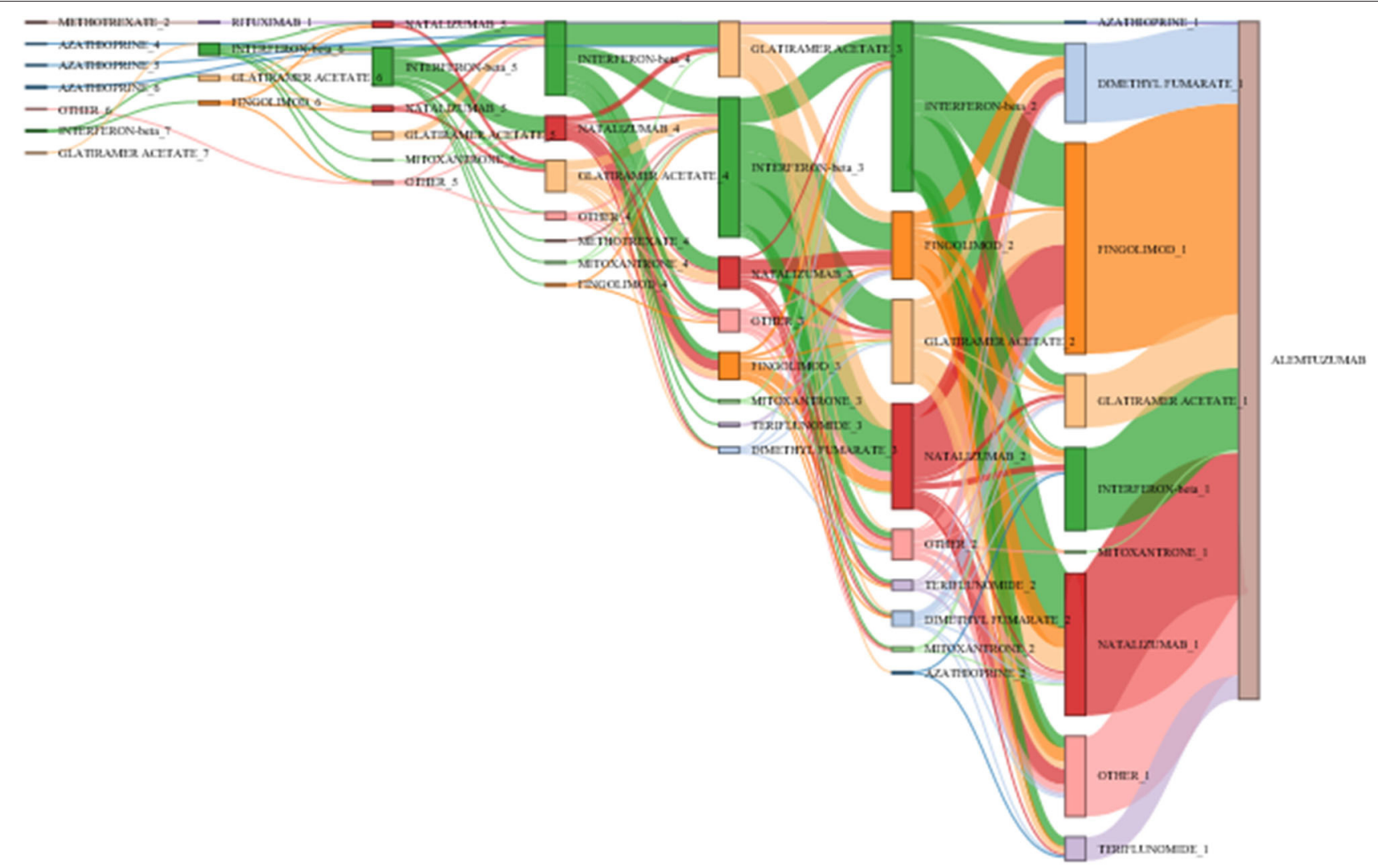

FIGURE 5 | Pathways of disease-modifying treatments (DMTs) before final switch to alemtuzumab. The figure illustrates the various treatment pathways as in Figure 4. By moving the cursor over the connecting ribbons, the respective number of patients treated with the previous DMT are indicated. The number following the DMT name indicates the position in the treatment sequence. The bars can be moved vertically to change the view of the Sankey plot.

value, and nearly $90 \%$ had a disease duration of $10+$ years (Figure 3D).

The MSSS combines EDSS and disease duration and is considered to be a powerful method for comparing disease progression using single assessment data (30). The score predicts disease severity over time (31). Figures 3A-D show the scatterplot of MSSS vs. number of relapses in the 12 months before inclusion, in patients with no, one, two, or more DMTs at baseline. In all subgroups, there was a peak of one or two relapses and a similar distribution with a predominance of lower MSSS values. There is no distinct pattern of medication use in the various groups. However, escalation therapy is more often used in patients with a higher number of DMTs.

\section{Visualization of Treatment Pathways}

Among the pretreated patients, 214 different treatment sequences were documented. Table 3 shows the 15 most frequent pretreatments and pathways in descending order.

Duration of previous therapy was reported in $55 \%$ of patients. Among these, in $<5 \%$, duration was $<3$ months. Figure 4 visualizes the main treatment pathways, which finally end up in 623 (pretreated) patients displayed in the blue alemtuzumab column on the right.
Figure 5 shows the same plot in HTML format in which the cursor roll-over the connecting ribbon will indicate the respective number of DMTs and the sequence number before alemtuzumab. The nodes can also be shifted vertically to change the view of the Sankey plot.

\section{Concomitant Diseases}

Concomitant diseases at baseline were reported in $30.0 \%$ of patients (Table 4). The System Organ Classes that were most frequently affected were psychiatric disorders (11.6\%), metabolism and nutrition disorders (10.0\%), and immune system disorders (4.6\%). The latter comprised mostly allergies but also one case of autoimmune disorder. As relevant disease (which prevent therapy as specified in the latest update of the Lemtrada ${ }^{\circledR}$ SmPC in January 2020), thyroid diseases were named in 31 cases, nephropathy in 2 cases, and immune thrombocytopenic purpura (ITP) in 1 case (Table 5).

There were no patients with history of angina pectoris, myocardial infarction, or stroke at baseline.

\section{DISCUSSION}

The present analysis focused on the detailed characterization of MS patients who, irrespective of the type of prior treatment 
TABLE 4 | Concomitant disease by system organ class.

\begin{tabular}{|c|c|c|}
\hline soc & $\begin{array}{c}\text { Total } \\
(N=883) \\
n\end{array}$ & $\%$ \\
\hline Any disease & 344 & 39.0 \\
\hline $\begin{array}{l}\text { Blood and lymphatic system } \\
\text { disorders }\end{array}$ & 12 & 1.4 \\
\hline Cardiac disorders & 13 & 1.5 \\
\hline $\begin{array}{l}\text { Congenital, familial, and genetic } \\
\text { disorders }\end{array}$ & 24 & 2.7 \\
\hline Ear and labyrinth disorders & 5 & 0.6 \\
\hline Endocrine disorders & 18 & 2.0 \\
\hline Eye disorders & 29 & 3.3 \\
\hline Gastrointestinal disorders & 25 & 2.8 \\
\hline $\begin{array}{l}\text { General disorders and } \\
\text { administration site conditions }\end{array}$ & 18 & 2.0 \\
\hline Hepatobiliary disorders & 7 & 0.8 \\
\hline Immune system disorders & 41 & 4.6 \\
\hline Infections and infestations & 28 & 3.2 \\
\hline $\begin{array}{l}\text { Injury, poisoning and procedural } \\
\text { complications }\end{array}$ & 14 & 1.6 \\
\hline Investigations & 13 & 1.5 \\
\hline Metabolism and nutrition disorders & 88 & 10.0 \\
\hline $\begin{array}{l}\text { Musculoskeletal and connective } \\
\text { tissue disorders }\end{array}$ & 43 & 4.9 \\
\hline $\begin{array}{l}\text { Neoplasms benign, malignant, and } \\
\text { unspecified }\end{array}$ & 14 & 1.6 \\
\hline Nervous system disorders & 114 & 12.9 \\
\hline $\begin{array}{l}\text { Pregnancy, puerperium, and } \\
\text { perinatal conditions }\end{array}$ & 1 & 0.1 \\
\hline Psychiatric disorders & 102 & 11.6 \\
\hline Renal and urinary disorders & 30 & 3.4 \\
\hline $\begin{array}{l}\text { Reproductive system and breast } \\
\text { disorders }\end{array}$ & 10 & 1.1 \\
\hline $\begin{array}{l}\text { Respiratory, thoracic, and } \\
\text { mediastinal disorders }\end{array}$ & 31 & 3.5 \\
\hline $\begin{array}{l}\text { Skin and subcutaneous tissue } \\
\text { disorders }\end{array}$ & 28 & 3.2 \\
\hline Surgical and medical procedures & 28 & 3.2 \\
\hline Vascular disorders & 45 & 5.1 \\
\hline
\end{tabular}

SOC, system organ class (from the Medical Dictionary for Regulatory Activities).

and the MS duration, are finally treated with alemtuzumab. The data complement the body of evidence from 1,500 patients that received alemtuzumab in the randomized controlled trials [CAMMS223 (9), CARE-MS I (10), and CARE-MS II (11)].

Compared to the initial alemtuzumab registration studies, the treament landscape and armamentarium of drugs have substantially changed, which needs to be considered in the interpretation of results. Compared with the baseline characteristics from the pivotal CARE-MS I and CARE-MS II trials, patients in TREAT-MS at enrollment had a comparable mean duration of disease since first symptoms (CARE-MS I, 2.1 years; CARE-MS II, 4.5 years; TREAT-MS, 3.4 years), a higher percentage with EDSS score $>3$ (CARE-MS I, 2\%; CARE-MS
TABLE 5 | Diseases of particular interest.

\begin{tabular}{lcc}
\hline Disease & $\boldsymbol{n}$ & $\begin{array}{r}\text { \% Of total } \\
(\mathbf{N}=\mathbf{8 8 3})\end{array}$ \\
\hline $\begin{array}{l}\text { Immune thrombocytopenic } \\
\text { purpura }\end{array}$ & 1 & 0.1 \\
$\begin{array}{l}\text { Nephropathy } \\
\text { Thyroid diseases }\end{array}$ & 2 & 0.2 \\
Hypothyroidism & 53 & \\
Hyperthyroidism & 10 & 6.2 \\
Hashimoto's thyroiditis & 11 & 1.2 \\
Graves' disease (Basedow) & 2 & 1.3 \\
Other & 12 & 0.2 \\
\hline
\end{tabular}

Values are $n$ and percentages of total.

II, 31\%; TREAT-MS, 37\%), a higher percentage who received treatment with fingolimod (only introduced in 2011: CARE-MS I and II, 0\%; TREAT-MS, 35\%) or natalizumab (CARE-MS I, $0 \%$; CARE-MS II, 4\%; TREAT-MS, $35 \%$ ) prior to enrollment. They tended to have similar relapse activity in the 2 years before alemtuzumab treatment initiation. Furthermore, in TREAT-MS, the sex and age distribution at baseline was similar to the two registration studies. Generally, patients with more advanced MS are treated with alemtuzumab under clinical practice conditions in Germany. However, every seventh patient was treatment naive prior to alemtuzumab initiation.

In line with the many treatment options for MS patients available today, a great variety of pretreatment patterns were documented. The Sankey diagram visualizes this diversity, over time and across DMTs. Few typical patterns emerged, with switches from IFN-beta to natalizumab or fingolimod and from natalizumab to fingolimod being the most eminent ones.

The relatively high number of patients recruited from centers in all parts of the country and different types of centers $(51.8 \%$ resident neurologists, $48.2 \%$ from various types and sizes of hospitals) is a strength of the study. It describes "typical" alemtuzumab patients as treated under real-life conditions; however, physicians may have assigned patients to the study based on the severity of their disease, on the observation that they did not respond well to other drugs, or the presence of complex comorbidities. These factors might lead to a non-representative study population.

Based on the assessment of the periodic safety update report (PSUSA) for alemtuzumab, in 2020, contraindications were added to the SmPC, in particular relating to cardiovascular disease (including history of stroke, angina pectoris, and myocardial infraction) and concomitant autoimmune diseases besides MS (32). While no patients had the named cardiovascular disease and only few had autoimmune diseases at baseline, the results of the present cohort will be an important contribution to the alemtuzumab safety database. 
In conclusion, the present analysis revealed a broad variety of different treatment sequences before the final switch to alemtuzumab. In comparison to the pivotal phase 2 and 3 studies, RRMS patients starting alemtuzumab treatment had a longer disease duration in real-world conditions.

Recently, a dual-center retrospective study from Germany in 170 patients treated with alemtuzumab (PROGRAM ${ }^{\mathrm{MS}}$ ) described the pretreatment ( 35 none, 52 basic, 50 natalizumab, 33 fingolimod) and found differences in treatment responses based on the previous use of DMT (33). In the future, linking treatment sequences or other baseline characteristics with effectiveness and safety outcomes might be useful to support treatment decisions $(34,35)$.

\section{DATA AVAILABILITY STATEMENT}

The datasets generated and/or analyzed during the current study are available from the corresponding author on reasonable request.

\section{ETHICS STATEMENT}

The studies involving human participants were reviewed and approved by Ethikkommission der Universitäsklinik Dresden. The patients/participants provided their written informed consent to participate in this study.

\section{REFERENCES}

1. Stankiewicz JM, Weiner HL. An argument for broad use of high efficacy treatments in early multiple sclerosis. Neurol Neuroimmunol Neuroinflamm. (2020) 7:e636. doi: 10.1212/NXI.0000000000000636

2. Giovannoni G. Disease-modifying treatments for early and advanced multiple sclerosis: a new treatment paradigm. Curr Opin Neurol. (2018) 31:233-43. doi: 10.1097/WCO.0000000000000561

3. Hassoun L, Eisele J, Thomas K, Ziemssen T. Hands on Alemtuzumabexperience from clinical practice: whom and how to treat. Mult Scler Demyelinating Disord. (2016) 1:10. doi: 10.1186/s40893-016-0011-1

4. Ziemssen T, Thomas K. Alemtuzumab in the long-term treatment of relapsing-remitting multiple sclerosis: an update on the clinical trial evidence and data from the real world. Ther Adv Neurol Disord. (2017) 10:343-59. doi: $10.1177 / 1756285617722706$

5. Ruck T, Bittner S, Wiendl H, Meuth SG. Alemtuzumab in multiple sclerosis: mechanism of action and beyond. Int J Mol Sci. (2015) 16:16414-39. doi: 10.3390/ijms160716414

6. Thomas K, Eisele J, Rodriguez-Leal FA, Hainke U, Ziemssen T. Acute effects of alemtuzumab infusion in patients with active relapsingremitting MS. Neurol Neuroimmunol Neuroinflamm. (2016) 3:e228. doi: 10.1212/NXI.0000000000000228

7. Akgun K, Blankenburg J, Marggraf $M$, Haase $R$, Ziemssen $T$. Event-driven immunoprofiling predicts return of disease activity in alemtuzumab-treated multiple sclerosis. Front Immunol. (2020) 11:56. doi: 10.3389/fimmu.2020.00056

8. Wiendl H, Kieseier B. Multiple sclerosis: reprogramming the immune repertoire with alemtuzumab in MS. Nat Rev Neurol. (2013) 9:125-6. doi: $10.1038 /$ nrneurol.2013.2

9. Camms 223 Trial Investigators, Coles AJ, Compston DA, Selmaj KW, Lake SL, Moran S, et al. Alemtuzumab vs. interferon beta-1a in early multiple sclerosis. N Engl J Med. (2008) 359:1786-801. doi: 10.1056/NEJMoa0802670

10. Cohen JA, Coles AJ, Arnold DL, Confavreux C, Fox EJ, Hartung HP, et al. Alemtuzumab versus interferon beta $1 \mathrm{a}$ as first-line treatment for patients with

\section{AUTHOR CONTRIBUTIONS}

TZ and UE developed the study design. FH, SR, and RW participated in the design of the study and contributed to the interpretation of results and the manuscript. RW initiated the drafting of the report and wrote the manuscript. All authors read and approved the final version of this manuscript.

\section{FUNDING}

This study was sponsored by Sanofi-Aventis Deutschland GmbH, Neu-Isenburg, Germany. Financial support for medical editorial assistance by 3P Consulting was provided by Sanofi-Aventis Deutschland GmbH.

\section{ACKNOWLEDGMENTS}

The authors and Sanofi Genzyme thank the patients for their participation in the study as well as the TREAT-MS study team. Input to the interpretation of results and to the first draft of the manuscript was provided by David Pittrow, MD, $\mathrm{PhD}$, from 3P Consulting, Seefeld, Germany. Statistical analyses were performed by E. Grünewald, Winicker Norimed GmbH, Nuremberg, Germany.

relapsing-remitting multiple sclerosis: a randomised controlled phase 3 trial. Lancet. (2012) 380:1819-28. doi: 10.1016/S0140-6736(12)61769-3

11. Coles AJ, Twyman CL, Arnold DL, Cohen JA, Confavreux C, Fox EJ, et al. Alemtuzumab for patients with relapsing multiple sclerosis after diseasemodifying therapy: a randomised controlled phase 3 trial. Lancet. (2012) 380:1829-39. doi: 10.1016/S0140-6736(12)61768-1

12. Havrdova E, Arnold DL, Cohen JA, Hartung HP, Fox EJ, Giovannoni $\mathrm{G}$, et al. Alemtuzumab CARE-MS I 5-year follow-up: durable efficacy in the absence of continuous MS therapy. Neurology. (2017) 89:1107-16. doi: 10.1212/WNL.0000000000004313

13. Coles AJ, Cohen JA, Fox EJ, Giovannoni G, Hartung HP, Havrdova E, et al. Alemtuzumab CARE-MS II 5-year follow-up: efficacy and safety findings. Neurology. (2017) 89:1117-26. doi: 10.1212/WNL.0000000000004354

14. Steingo B, Al Malik Y, Bass AD, Berkovich R, Carraro M, Fernandez $\mathrm{O}$, et al. Long-term efficacy and safety of alemtuzumab in patients with RRMS: 12-year follow-up of CAMMS223. J Neurol. (2020) 267:3343-53. doi: 10.1007/s00415-020-09983-1

15. Ziemssen T, Bass AD, Berkovich R, Comi G, Eichau S, Hobart J, et al. Efficacy and safety of alemtuzumab through 9 years of follow-up in patients with highly active disease: post-hoc analysis of CARE-MS I and II patients in the TOPAZ extension study. CNS Drugs. (2020) 34:973-88. doi: 10.1007/s40263-020-00749-x

16. U.S. Food and Drug Administration (FDA). Lemtrada Prescrribing Information. Available online at: http://www.accessdata.fda.gov/drugsatfda_ docs/label/2014/103948s5139lbl.pdf (accessed May 20, 2021).

17. European Medicines Agency. Lemtrada Article 20 Procedure-Measures to Minimise Risk of Serious Side Effects of Multiple Sclerosis Medicine Lemtrada. Available online at: https:/www.ema.europa.eu/documents/ referral/lemtrada-article-20-procedure-measures-minimise-risk-seriousside-effects-multiple-sclerosis_en-0.pdf (accessed May 20, 2021).

18. European Medicines Agency (EMA). Lemtrada. Summary of Product Characteristics (SmPC). (2020). Available online at: https://www.ema.europa. eu/en/medicines/human/EPAR/lemtrada\#product-information-section (accessed May 20, 2021). 
19. Le Page E, Deburghgraeve V, Lester MA, Cardiet I, Leray E, Edan G. Alemtuzumab as rescue therapy in a cohort of 16 aggressive multiple sclerosis patients previously treated by mitoxantrone: an observational study. J Neurol. (2015) 262:1024-34. doi: 10.1007/s00415-015-7653-3

20. Tuohy O, Costelloe L, Hill-Cawthorne G, Bjornson I, Harding K, Robertson N, et al. Alemtuzumab treatment of multiple sclerosis: longterm safety and efficacy. J Neurol Neurosurg Psychiatry. (2015) 86:208-15. doi: 10.1136/jnnp-2014-307721

21. Prosperini L, Annovazzi P, Boffa L, Buscarinu MC, Gallo A, Matta M, et al. No evidence of disease activity (NEDA-3) and disability improvement after alemtuzumab treatment for multiple sclerosis: a 36-month real-world study. $J$ Neurol. (2018) 265:2851-60. doi: 10.1007/s00415-018-9070-X

22. Ziemssen T, Rothenbacher D, Kuhle J, Berger T. Real-world evidence : benefits and limitations in multiple sclerosis research. Nervenarzt. (2017) 88:1153-8. doi: 10.1007/s00115-017-0387-y

23. Ziemssen T, Hillert J, Butzkueven H. The importance of collecting structured clinical information on multiple sclerosis. BMC Med. (2016) 14:81. doi: 10.1186/s12916-016-0627-1

24. Ziemssen T, Engelmann U, Jahn S, Leptich A, Kern R, Hassoun L, et al. Rationale, design, and methods of a non-interventional study to establish safety, effectiveness, quality of life, cognition, health-related and work capacity data on Alemtuzumab in multiple sclerosis patients in Germany (TREATMS). BMC Neurol. (2016) 16:109. doi: 10.1186/s12883-016-0629-9

25. D'Amico E, Haase R, Ziemssen T. Review: patient-reported outcomes in multiple sclerosis care. Mult Scler Relat Disord. (2019) 33:61-6. doi: 10.1016/j.msard.2019.05.019

26. Guy W. Clinical global impressions. In: National Institute of Mental Health, editor. ECDEU Assessment for Psychopharmacology, 1st ed. Rockville, MD: National Institute of Mental Health (1976). p. 221-7.

27. Ziemssen T, Kern R, Voigt I, Haase R. Data collection in multiple sclerosis: the MSDS approach. Front Neurol. (2020) 11:445. doi: 10.3389/fneur.2020.00445

28. Ziemssen T, Kempcke R, Eulitz M, Grossmann L, Suhrbier A, Thomas $\mathrm{K}$, et al. Multiple sclerosis documentation system (MSDS): moving from documentation to management of MS patients. J Neural Transm. (2013) 120:S61-6. doi: 10.1007/s00702-013-1041-x

29. Siegel CA, Yang F, Eslava S, Cai Z. Treatment pathways leading to biologic therapies for ulcerative colitis and Crohn's disease in the United States. Clin Transl Gastroenterol. (2020) 11:e00128. doi: 10.14309/ctg.0000000000000128

30. Roxburgh R, Seaman S, Masterman T, Hensiek AE, Sawcer S, Vukusic S, et al. Multiple Sclerosis Severity Score: using disability and disease duration to rate disease severity. Neurology. (2005) 64:1144-51. doi: 10.1212/01.WNL.0000156155.19270.F8

31. Pachner AR, Steiner I. The multiple sclerosis severity score (MSSS) predicts disease severity over time. J Neurol Sci. (2009) 278:66-70. doi: 10.1016/j.jns.2008.11.020
32. European Agency for the Evaluation of Medicinal Products (EMA). Measures to Minimise Risk of Serious Side Effects of Multiple Sclerosis Medicine Lemtrada. Available online at: https://www.ema.europa.eu/en/medicines/ human/referrals/lemtrada (accessed May 20, 2021).

33. Pfeuffer S, Ruck T, Pul R, Rolfes L, Korsukewitz C, Pawlitzki M, et al. Impact of previous disease-modifying treatment on effectiveness and safety outcomes, among patients with multiple sclerosis treated with alemtuzumab. J Neurol Neurosurg Psychiatry. (2021). doi: 10.1136/jnnp-2020-325304. [Epub ahead of print].

34. Ziemssen T, Kern R, Thomas K. Multiple sclerosis: clinical profiling and data collection as prerequisite for personalized medicine approach. BMC Neurol. (2016) 16:124. doi: 10.1186/s12883-0160639-7

35. Voigt I, Inojosa $\mathrm{H}$, Dillenseger $\mathrm{A}$, Haase $\mathrm{R}$, Akgün $\mathrm{K}$, Ziemssen $\mathrm{T}$. Digital Twins for Multiple Sclerosis. Front Immunol. (2021) 12:669811. doi: 10.3389 /fimmu.2021.669811

Conflict of Interest: RW and UE are employees of Sanofi. TZ received consulting and/or speaking fees (Almirall, Bayer, Biogen, Merck, Novartis, Roche, Sanofi, and Teva) and grant/research support (Biogen, Novartis, Sanofi, and Teva). FH received consulting and/or speaking fees (Alexion, Bayer, Biogen, CSL Behring, DIAMED Medizintechnik, Grifols, Ipsen, Merck, Novartis, Roche, Sanofi and Teva) and grant/research support (Bayer, Biogen, Merck, Novartis). SR received consulting and/or speaking fees (Biogen, Merck, Novartis, Roche, Sanofi) and grant/research support (Biogen, Merck, Celgene).

The authors declare that this study received funding from Sanofi-Aventis Deutschland GmbH. The funder was involved in the study design, analysis, interpretation of data, the writing of this article and the decision to submit it for publication.

Publisher's Note: All claims expressed in this article are solely those of the authors and do not necessarily represent those of their affiliated organizations, or those of the publisher, the editors and the reviewers. Any product that may be evaluated in this article, or claim that may be made by its manufacturer, is not guaranteed or endorsed by the publisher.

Copyright (c) 2021 Ziemssen, Hoffmann, Richter, Engelmann and White. This is an open-access article distributed under the terms of the Creative Commons Attribution License (CC BY). The use, distribution or reproduction in other forums is permitted, provided the original author(s) and the copyright owner(s) are credited and that the original publication in this journal is cited, in accordance with accepted academic practice. No use, distribution or reproduction is permitted which does not comply with these terms. 